NBER WORKING PAPER SERIES

\title{
FISCAL SHENANIGANS, TARGETED FEDERAL HEALTH CARE FUNDS, AND PATIENT MORTALITY
}

\author{
Katherine Baicker \\ Douglas Staiger \\ Working Paper 10440 \\ http://www.nber.org/papers/w10440 \\ NATIONAL BUREAU OF ECONOMIC RESEARCH \\ 1050 Massachusetts Avenue \\ Cambridge, MA 02138 \\ April 2004
}

This research was funded by NIA grant P01 AG19783-02. The authors thank Amitabh Chandra, Mark Duggan, Jonathan Skinner, and seminar participants at several seminars for helpful suggestions. The views expressed herein are those of the author(s) and not necessarily those of the National Bureau of Economic Research.

(C)2004 by Katherine Baicker and Douglas Staiger. All rights reserved. Short sections of text, not to exceed two paragraphs, may be quoted without explicit permission provided that full credit, including (C) notice, is given to the source. 
Fiscal Shenanigans, Targeted Federal Health Care Funds, and Patient Mortality

Katherine Baicker and Douglas Staiger

NBER Working Paper No. 10440

April 2004

JEL No. H0, I0

\section{ABSTRACT}

The federal government spends billions of dollars each year on programs designed to increase the resources available to hospitals that serve the poor. This paper explores the intended and unintended effects of such targeted funds. First, how do these funds distort the behavior of state and local governments who wish to appropriate the funds for other uses? Second, to the extent that these funds do increase resources in the targeted hospitals, do patients benefit? We use the rapid and uneven growth in Medicaid Disproportionate Share Hospital (DSH) payments across states and hospitals to answer these questions. We identify states that were most able to appropriate DSH funds and show that, while DSH payments to public hospitals in these states were systematically diverted, DSH payments to other hospitals and in other states were not diverted. Additional resources that were made available to hospitals (rather than appropriated by the state) were associated with significant declines in infant and post-heart attack mortality. A range of evidence suggests that these improvements were due to better hospital care. Overall, our analysis implies that public subsidies can be an effective mechanism for improving medical care and outcomes for the poor, but that the impact is limited by the ability of state and local government to divert the targeted funds.

Katherine Baicker

Dartmouth College

Department of Economics

6106 Rockefeller Hall

Hanover, NH 03755

and NBER

kbaicker@dartmouth.edu
Douglas Staiger

Dartmouth College

Department of Economics

Rockefeller Hall, Room 322

Hanover, NH 03755-3514

and NBER

dstaiger@dartmouth.edu 


\section{INTRODUCTION}

The federal government spends billions of dollars each year on programs designed to improve health care for the poor and disadvantaged. We explore the intended and unintended effects of such targeted funds. First, how do these funds distort the behavior of state and local governments who wish to appropriate the funds for other uses? Second, to the extent that these funds do increase resources devoted to the targeted population, do patients benefit? The answers to these two questions shed light on whether (and at what cost) federal funds targeted in this way are able to achieve their goals.

We evaluate the effects of a large public program subsidizing hospitals serving the poor. These safety-net hospitals were financially squeezed beginning in the 1980s as the number of uninsured patients rose and reimbursements for insured patients were constrained by increasingly cost-conscious insurance providers. Beginning in the late 1980s, state and federal governments responded to the increasing burden on safety-net hospitals by incorporating direct subsidies to these hospitals into Medicare and Medicaid. In theory, these subsidies were intended to assure the continued survival of safety net hospitals and thereby maintain access to high quality care for poor and uninsured patients. Surprisingly little is known about whether these public subsidies have had any impact on patient care, despite spending of nearly $\$ 200$ billion during the 1990s on these programs by state and federal governments.

We use a new source of nationwide data on subsidies provided to hospitals through the Medicaid Disproportionate Share (DSH) program to look at the impact that these funds had on patient mortality. We begin by investigating the extent to which state governments appropriated these DSH funds through creative financing mechanisms. Recent reports by the GAO (2000) and Coughlin et al. (2000) suggest that state governments were able to capture much of the DSH payments through various schemes, and we present additional direct evidence that these financial 
"shenanigans" went on in government-owned hospitals in many but not all states. We use the results of this analysis to separate out funds captured by the state from those that actually went to hospitals, and then relate the amount of "effective" DSH payments (subsidies not captured by the state) to changes in patient mortality over the decade in which the DSH program was introduced. We find that effective subsidies were significantly related to declines in infant and post heartattack mortality. This effect came primarily through improvements in survival during hospitalization, not through later mortality or through declines in incidence of low-weight births or heart attacks, suggesting that improved medical care in the hospital was the causal factor.

Our evidence highlights the importance of heterogeneity in state responses to program incentives. For example, previous work by Duggan (2000) evaluating California's DSH program found that public subsidies to safety-net hospitals did not improve infant mortality rates because subsidies of over $\$ 1$ billion per year did not translate into increased spending on patients. Our results suggest that most of the DSH money in California was captured by the state, so that there was little net impact on patient care. In contrast, however, we find evidence that other states were less able to divert the targeted funds, and DSH money in these states was associated with improved patient outcomes. Overall, our analysis suggests that public subsidies can be an effective mechanism for improving medical care and outcomes for the poor, but that the impact is limited by the ability of state and local government to divert the targeted funds.

\section{The Disproportionate Share Program}

The Medicare and Medicaid Disproportionate Share Hospital programs were created in 1986 and 1989 to compensate certain hospitals for the care they provided to under- and uninsured patients. Hospitals serving more of these patients relative to the fully-insured were believed to have less capacity to offset uncompensated care costs themselves, since there were fewer paying patients over which to spread the burden. The DSH programs increased the per- 
patient reimbursement received by hospitals with a high fraction of Medicaid or uninsured patients. Medicaid DSH grew rapidly, reaching payments of roughly $\$ 17$ billion by 1992 before stabilizing. Payments through the Medicare DSH program were $\$ 4.5$ billion in 1998 (Nicholson and Song, 1991), while Medicaid DSH payments were $\$ 16$ billion - representing 9 percent of federal Medicaid vendor payments.

Unlike the federal Medicare program, Medicaid is a joint federal-state program. Each state has much freedom to determine eligibility, generosity of benefits, and payment structure for its Medicaid recipients. The federal government matches state Medicaid expenditures at a rate based on state per capita income, with wealthier states receiving a match of 50 percent and the poorest state receiving a match rate of up to 82 percent. While Medicare DSH payments to hospitals are determined by federal formula, Medicaid DSH payments are determined by individual states, and matched by the federal government.

This structure for many years provided the opportunity for savvy states to extract greater federal matching funds without increasing their net Medicaid expenditures. Throughout the 1990s, states exploited different loopholes in the federal DSH statutes to increase the effective match rate. As the GAO reports $(1994,2000)$ and Coughlin, $\mathrm{Ku}$, and Kim (2000) show, many states extracted billions in "extra" Medicaid DSH payments.

One such mechanism used in the early 1990s was the imposition of provider-specific taxes. For example, a state could impose a tax of $\$ 1$ billion dollars on a particular hospital. It could then pay the hospital \$1 billion dollars in DSH payments, which would be matched by the federal government with at least $\$ 500$ million - a net increase in state resources, accompanied by no change in resources to the hospital. 1991 and 1993 legislation curtailed the use of such schemes, and limited the ability of states to divert DSH funds paid to private hospitals (Coughlin et al., 2000). 
By the mid 1990s, the primary mechanisms through which a state could appropriate DSH funds involved payments to government-owned hospitals. The most direct mechanism was to pay DSH funds directly to hospitals run by the state. Interviews with state officials suggest that most of the DSH payments to state hospitals were appropriated by the state and resulted in no net increase of funds for patient care ( $\mathrm{Ku}$ and Coughlin, 1995). This type of self-dealing was common in mental health and long-term care facilities where state ownership is common, but was limited in acute-care facilities because fewer than 5\% of acute-care hospital beds are in state owned facilities (Coughlin et al, 2000).

A less direct mechanism that was more commonly used in acute care settings was to pay DSH funds to public hospitals run by county and local governments, and then divert the funds back to the state through an intergovernmental transfer (IGT). Intergovernmental transfers are direct fund transfers between different levels of government that are both legal and commonly used in government finance. In the context of DSH, however, IGT were allegedly used to circumvent the intent of the Medicaid DSH program. For example, the GAO (1994) documented the transfer of a $\$ 277$ million federal/state DSH payment to a Michigan county nursing facility, which wired \$271 million back to the state the same day. Both regulation and legislation in the late 1990s curtailed the use of some of the most obvious schemes, and the Balanced Budget Act of 1997 implemented reforms aimed at reining in the overall size of the DSH program (although many of these restrictions did not take effect until after 2000). Nevertheless, there is widespread belief that many of these schemes, and IGT schemes in particular, continue to be used widely.

\section{A Model of State Behavior}

Because Medicaid is administered by the states, each state is free to determine both the amount of DSH money to distribute and the rules for deciding which hospitals receive these funds, subject to broad guidelines established by the federal government. In order to understand 
the incentives influencing state governments to appropriate DSH funds for other uses, we develop a simple model of state behavior. The model has three key features. First, we assume that the state derives some benefit from paying subsidies to hospitals that serve the poor, presumably in the form of improved access and health outcomes among the population served by these hospitals. Second, we assume that the state can expropriate any amount of DSH funds paid to public (but not private) hospitals through the use of IGT. Finally, we assume that the federal rules constrain the state so that it must make similar DSH payments to all public and private hospitals that serve a similar proportion of poor patients. Thus, for each set of hospitals serving a similar proportion of poor patients, the state must determine the level of the DSH payment (if any) along with the amount of IGT to divert from the public hospitals.

Let $\mathrm{X}$ represent the net payment per patient made to a hospital (DSH net of any IGT), and let $\rho$ represent the proportion of poor patients served in the hospital. Suppose that the benefits of the payments are given by $\rho f(X)$, where $f^{\prime}>0$ and $f^{\prime \prime}<0$. In other words, the benefits of these payments are larger in hospitals that serve more poor patients, and are increasing in the amount of the payment but with declining marginal benefit. In private hospitals, which pay no IGT, the net payment is simply the DSH amount (per patient), so that $\mathrm{X}=\mathrm{DSH}$. In public hospitals, the payment is net of IGT so that $\mathrm{X}=\mathrm{DSH}-\mathrm{IGT}$ (where IGT is also per patient). If public hospitals account for a proportion $\pi$ of all hospitals, then the total benefits of DSH payments to hospitals with a given $\rho$ are given by:

$$
\text { Benefits }=(1-\pi) \rho f(D S H)+\pi \rho f(D S H-I G T)
$$

Thus, the benefits are a weighted average of the benefits at private and public hospitals.

The net cost of DSH payments depends on two factors. First, the federal government pays a portion of all Medicaid costs (the Federal Medical Assistance Percentage or FMAP) which varies from 0.5 to 0.82 depending on the income of each state. Second, the state receives 
a proportion of the DSH money back in the form of IGT, where the amount depends on the proportion of hospitals that are public. Thus, the total net cost to the state is given by:

$$
\text { Costs }=D S H(1-F M A P)-\pi I G T
$$

Where the first term represents the state direct contribution, while the second term represents the funds diverted back to the state through the IGT mechanism.

The state chooses the DSH payment going to all hospitals and the IGT payment coming from public hospitals to maximize its benefits net of costs. As a benchmark, we begin by considering a state with no public hospitals $(\pi=0)$ or, equivalently, a state that chooses not to use the IGT mechanism. In this case, the state chooses DSH to satisfy the first order condition given by:

$$
\rho f^{\prime}(D S H)=1-F M A P
$$

The left hand side of equation 3 represents the marginal benefits of payments to the hospitals, while the right hand side represents the marginal cost of these payments to the state (i.e., the state share). Thus, because of the federal subsidy, the state increases DSH payments to the point where the marginal benefit of an additional dollar is less than a dollar. Moreover, because the marginal benefit of any DSH payment increases with $\rho$, the state will choose to make larger DSH payments to hospitals serving a larger proportion of poor patients. Hospitals with a sufficiently low $\rho$ will be at a corner solution with $\mathrm{DSH}=0$, i.e. the state will choose to make no $\mathrm{DSH}$ payments to hospitals serving few poor patients.

In the more general case in which the state has public hospitals, the state chooses DSH and IGT to satisfy two first order conditions that can be simplified to be:

$$
\begin{gathered}
\rho f^{\prime}(D S H-I G T)=1 \\
\rho f^{\prime}(D S H)=1-\frac{F M A P}{1-\pi}
\end{gathered}
$$


These two first order conditions have a very natural interpretation. Equation (4a) states that the marginal benefit of the net payments made to public hospitals is equal to 1 - since the state controls the net amount going to public hospitals through the unsubsidized IGT, the state will use the IGT to reduce the net payment until the marginal dollar returns one dollar in marginal benefits. Thus, any increase in the DSH payment is undone dollar-for-dollar by IGT in the public hospitals.

Equation (4b) implies that the marginal benefit of the payments made to private hospitals is set equal to the net marginal cost of these payments to the state. When there are no public hospitals $(\pi=0)$, the marginal cost is simply the state share (1-FMAP). With public hospitals, the net marginal cost is lower since any increase in DSH payments is fully paid back to the state by the proportion of hospitals $(\pi)$ that are public. In the extreme, when the proportion of hospitals that are private $(1-\pi)$ is smaller than the federal match, the marginal cost of higher DSH payments becomes negative, i.e. at the margin the state finances more than the entire state contribution through the IGT mechanism, and the DSH program becomes a money machine for the state. In this case, federal caps on DSH payments to hospitals would be binding, as states would otherwise increase DSH payments without bound.

Figure 1 illustrates the solution to the model graphically. As the state raises DSH payments, the marginal benefit declines. The state sets DSH payments so that the marginal benefit equals the marginal cost in private hospitals $(1-\mathrm{FMAP} /(1-\pi))$, and then sets IGT so that the marginal benefit equals the marginal cost in public hospitals (1). The use of the IGT mechanism lowers the marginal cost in private hospitals compared to what it would have been in the absence of IGT (1-FMAP), and therefore increases the DSH payments that a state is willing to make.

The assumptions of this model capture several features of the current DSH program. States' DSH payment formulas are usually based on the fraction of each hospital's patients who 
are uninsured or covered by Medicaid. States have a great deal of latitude in creating payment formulas - for example, California makes payments only to hospitals with a proportion of uninsured/Medicaid patients above a certain threshold, and the payments are an increasing function of that proportion above the threshold - but must generally treat hospitals with similar proportions of poor patients similarly. There is also now an overall cap on DSH payments that limits a state's ability to extract federal dollars. Moreover, the most widely publicized examples of financial shenanigans involving IGT payments have occurred in non-acute care hospitals, were public ownership is the norm ( $\pi$ is high) and states are likely to face a negative marginal cost of increasing DSH payments..

This simple model also has a number of straightforward implications that help to identify which states were most likely using the IGT mechanism and that correspond well with observed state behavior. First, the model suggests that having a large proportion of public hospitals, particularly if those public hospitals are more likely to serve a large proportion of poor patients, will encourage states to use the IGT mechanism. Among states that use the IGT mechanism, we

would expect higher DSH payments. Moreover, holding the proportion of poor patients in a hospital $(\rho)$ constant, states using the IGT mechanism will raise DSH payments more if a larger proportion of hospitals are public. Thus, states using the IGT mechanism will tend to pay a larger proportion of their overall DSH payments to public hospitals.

\section{EMPIRICAL FRAMEWORK}

Our empirical analysis proceeds in three parts. We begin with an analysis of fiscal shenanigans at the state level, focusing on the factors that our model suggest should be associated with a state's use of intergovernmental transfers (IGT). In particular, we evaluate how states that used IGT differed from other states in terms of fundamental factors (existing state characteristics that facilitated the use of IGT) and in terms of other features of their DSH 
program that were likely to arise in response to the use of the IGT mechanism. The primary goal of this first part of the analysis is to identify the states that were most likely to be engaging in fiscal shenanigans with DSH money.

In the second part of the analysis, we decompose total DSH payments into "effective" and "ineffective" components, where effective DSH is defined as DSH payments that are most likely to increase the financial resources available to acute-care hospitals. In particular, we define effective DSH payments as those that are unlikely to be appropriated by the state, i.e. payments to private hospitals, or to county or local hospitals in states that were not appropriating the gains through IGT or similar strategies. The primary challenge in this part of the analysis is determining the extent to which each state was appropriating DSH funds from county hospitals.

In the last part of the analysis, we estimate the relationship between effective DSH funds and infant and post-heart attack mortality. In particular, we investigate whether counties receiving effective DSH payments in the late 1990s experienced a larger decline in mortality since the late 1980s compared to counties receiving either no DSH payments or ineffective DSH payments. Our analysis uses long differences (from a period just prior to the DSH program to a period following five years of stable DSH payments) to focus on long-run effects of DSH payments.

\section{A. Identifying States Engaging in Fiscal Shenanigans}

The goal of the first part of our analysis is to identify the states that were most likely to be engaging in fiscal shenanigans with DSH money through the use of inter-governmental transfers (IGT). Our model suggests several factors that should influence the extent that states engage in this behavior. For obvious reasons, a direct and reliable measure of the extent to which each state expropriated DSH funds is not available. Therefore, we consider three alternative state-level proxies that should be associated with the extent to which a state expropriated DSH 
funds. Our most direct proxy is whether the state self-reported that it used IGT to finance DSH payments in a survey of state Medicaid programs conducted by the Urban Institute (Coughlin et al, 2000). While this serves as a potential marker for states that were using the IGT mechanism, it is only available for a subset of states that responded to the survey and one might question the accuracy of self-reports on this issue in the face of ongoing investigations into such schemes by the GAO and others. Our second proxy is the size of DSH payments in each state relative to its Medicaid and uninsured patient hospital days. A state that appropriated a fraction of DSH funds for its own uses had more incentive to increase the size of their DSH program, so the overall size of the DSH program (relative to the patients it was intended to serve) should be higher in states using the IGT mechanism. Our final proxy is the fraction of all DSH payments to acute care hospitals that went to county and other local-government hospitals. Any state that was appropriating DSH funds from county hospitals had a strong incentive to funnel funds toward these hospitals, so the proportion of these funds going to county hospitals should be higher in states using the IGT mechanism.

To evaluate the plausibility of these proxies we ran state-level regressions to determine whether each proxy was related to three state characteristics that our model suggests should have facilitated the use of IGT. First, to the extent that there were returns to scale in running the IGT scheme, states with larger populations should have been more likely to use the IGT. Such returns to scale would arise if setting up such a scheme required fixed costs in terms of time or hiring staff with sufficient financial savvy. A second important characteristic that should have facilitated the use of IGT was whether county hospitals accounted for a large fraction of hospital beds in the state. States with a larger share of county hospitals had relatively more county hospitals on which to operate the IGT mechanism (increasing the benefit of using IGT to the state) and relatively fewer private hospitals that might potentially also qualify for DSH payments (reducing the cost to the state). A final characteristic that should have facilitated the use of IGT 
was whether county hospitals differed from private hospitals in the proportion of patients that were Medicaid or uninsured. As discussed above, state rules for allocating DSH payments had to be at least superficially consistent with the original purpose of benefiting hospitals with a disproportionate share of poor patients. Thus, it was much easier for states to target DSH payments to county hospitals if poor patients were a much larger proportion of patients at county hospitals relative to private hospitals.

\section{B. Identifying Effective DSH Payments}

The goal of the second part of our analysis is to separate DSH payments into those payments that were likely to affect acute care hospitals, and those payments that were likely to be ineffective. There are two reasons that DSH payments may have been ineffective. First, a large fraction $(22 \%)$ of DSH payments went to non-acute hospitals that do not treat newborns or heart attack victims, primarily state institutions for mental disease. Second, DSH payments may have been ineffective if they were appropriated by the state.

The extent to which DSH payments were appropriated by the state varies by type of hospital and by state. As discussed above, DSH payments to state-owned acute care hospitals (14\% of all payments) were easily appropriated by the state because of the direct financial integration of the state and these hospitals. In contrast, it was difficult for states to appropriate DSH payments to private acute care hospitals (36\% of all DSH payments). Because private hospitals are independent entities, states could only extract DSH funds through formal means (observable to federal auditors) such as provider taxes or adjustments of other Medicaid payments. Since legislation in the early 1990s curtailed the use of such schemes, by the late 1990s it is unlikely that much of the DSH payments going to private hospitals were being appropriated by the state. The ability of states to appropriate DSH payments from local 
government hospitals (primarily county hospitals, accounting for $30 \%$ of DSH payments) was less clear, and depended on the extent to which each state used IGT or similar mechanisms.

In order to identify the proportion of DSH payments to county hospitals that were ineffective, we must know the extent to which states appropriated DSH payments from local government hospitals. To answer this question, we take an empirical approach that uses the relationship between DSH payments and the amount of IGT observed in county financial data. Figure 2 illustrates this relationship. When a typical state (with a 50\% federal match rate) makes a \$1 million DSH payment to a county hospital, the federal government will reimburse the state by $\$ 0.5$ million. Because county hospitals are financed as part of the parent county government, the \$1 million DSH payment will show up as intergovernmental revenue (from the state to the county) in county financial data. If the county hospital keeps a proportion of funds $(\delta)$, and returns the remainder $(1-\delta)$ to the state then this will appear as an intergovernmental expenditure in the county financial data. Thus, for every dollar in DSH payments there will be an increase of $\delta$ in net IGT to the county (the difference between revenues and expenditures) while the remainder $(1-\delta)$ represents ineffective DSH payments. Note also that the net cost of this transaction to the state is equal to the difference between $\delta$ and the federal Medicaid match rate, i.e. the DSH payment costs the state nothing so long as the county hospital only keeps the federal share and returns the state share.

To identify the extent to which states appropriated DSH payments from local government hospitals, we take an empirical approach. We have a number of potential indicators for whether a state was appropriating DSH payments from public hospitals (described above): the share of DSH payments going to government hospitals, the average DSH payment per Medicaid or uninsured patient, and estimates of the share of non-federal revenues paying for DSH in each state that come from IGT. The empirical question is which, if any, of these measures is a good indicator of states that are appropriating DSH payments from local public hospitals. 
To estimate $\delta$ we run regressions of the form:

$$
\begin{aligned}
& \Delta \text { netIGT }_{i,(97 / 99)-(87 / 89)}=\alpha_{s}+\theta\left(1-{\text { capturę }) \mathrm{DSH}_{i, \text { county, }(98 / 00)}}+\delta \text { capturę } \mathrm{DSH}_{i, \text { county, }(98 / 00)}\right. \\
& +\Gamma \Delta X_{i,(98 / 00)-(87 / 89)}+\varepsilon_{i}
\end{aligned}
$$

The dependent variable in this regression is the change in net IGT per capita for a county between the late 1980s (prior to DSH) and the late 1990s. We difference the data at the county level to remove any fixed county-level differences in net IGT, and we use a long difference beginning just prior to the introduction of the DSH program to focus on long-run impacts of DSH payments.

The key right hand side variable in this regression is the amount of DSH per capita going to county hospitals in the late 1990s. Note that this variable is in effect the difference in DSH payments between the late 1980s and the late 1990s, since there were no sizable DSH payments until the early 1990s. We interact the DSH variable with a dummy variable (capture) that indicates whether the state is likely to be using IGT to appropriate DSH payments. We construct the dummy "capture" a number of ways, based on our three proxy measures for whether a state was using IGT (discussed above). If these proxies are informative, then we would expect the effect of DSH on net IGT to be near one in states that are not capturing DSH payments $(\theta=1)$ and below one in states that capture a share of DSH payments $(\delta<1)$, with $\delta$ representing the effective fraction of DSH payments that were not appropriated by the state. Finally, the regression also controls for state fixed effects and changes in percent black, unemployment, and per capita income at the county level.

Note that our estimate of $\delta$ only measures the proportion of DSH funds that remain with the county, but not necessarily with the county hospital itself. Because county hospitals are financed as part of the parent county government, we do not observe transfers between the county government and its hospitals. Thus, we can observe through the county's net intergovernmental revenues the net increases in resources available to the county and its hospital, 
but not the fraction of that net increase devoted to hospital spending in particular. Thus, our estimates may overstate the extent to which DSH payments to county hospitals are effective.

\section{Estimating the Impact of Effective DSH Payments on Patient Mortality}

To estimate the relationship between DSH payments and patient mortality, we decompose total DSH payments into effective and ineffective payments and then run a regression of the change in mortality between the late 1980s and the late 1990s on the amount of each DSH going to the county in the late 1990s. Our analysis is done at the county (rather than hospital) level to avoid issues of patient selection across hospitals and because both the county financial data and the mortality data are only available at the county level. Separate regressions are run based on mortality rates derived for newborns (percent of infants that died within 28 days or 1 year of birth) and elderly patients with heart attacks (percent that died within 90 days or 1 year of heart attack). Mortality rates in both of these patient populations are believed to be sensitive to the quality of medical care provided in the hospital. Additional detail on how these variables are constructed is provided below.

The regression we run is of the form:

$$
\begin{aligned}
\Delta \mathrm{MR}_{i,(98 / 00)-(87 / 89)}= & \alpha_{s}+\beta_{1} \mathrm{DSH}_{i, \text { effective, }(98 / 00)}+\beta_{2} \mathrm{DSH}_{i, \text { ineffective },(98 / 00)} \\
& +\Gamma \Delta X_{i,(98 / 00)-(87 / 89)}+\varepsilon_{i}
\end{aligned}
$$

The dependent variable is the change in the mortality rate between the late 1980 s and the late 1990s. The regression also controls for state fixed effects and changes in the same county-level covariates. In the regression using infant mortality, we have also controlled for the change in the proportion of single parent households in the county.

The key independent variables are measures of effective and ineffective DSH per capita, where the coefficient on ineffective DSH is expected to be zero and the coefficient on effective DSH is expected to be negative (associated with declines in mortality). In states that do not 
appropriate DSH payments (capture=0), we define effective DSH as the sum of all DSH payments to private acute care hospitals plus DSH payments to county or district hospitals. In states that appropriate DSH payments (capture=1), we only include the effective fraction $(\delta)$ of DSH payments going to local government hospitals, where $\delta$ is the coefficient estimated in equation (5). Ineffective DSH is defined as the remaining DSH payments (to non-acute hospitals, state hospitals, and the ineffective fraction to local government hospitals in states with capture $=1)$.

\section{DATA}

Data for this analysis come from several different sources, and are summarized in Table 1. Analysis is performed at the county level, using data from the late 1980s and the late 1990s.

\section{A. DSH Payments}

Beginning in 1998, CMS requested that each state make available an annual report of the hospitals receiving DSH payments and the amount they received. Most states have complied with this request in at least one year since 1998. We matched the hospitals listed in these reports with their American Hospital Association identification number whenever possible, but some listings were ambiguous, and some states (such as Alabama and Michigan) reported aggregated figures that could not be used. Overall, we were able to match 90 percent of DSH dollars reported. Hospital allocations were then aggregated to the county level. When multiple years of data were available, the county values were averaged across years. After discarding Alaska, Hawaii, and the District of Columbia, we were left with data on DSH payments to 2579 (of the 3042) US counties. By matching hospital payments to AHA provider information from the Hospital File, we were able to calculate DSH payments at the county level by hospital ownership (public (state, county, district) versus private) and by hospital service (general, children's, 
psychiatric, etc.). We supplement this data with details on state-level DSH allocations and financing gathered by Coughlin et al. (2000), including information on the degree to which states used intergovernmental transfers from localities to finance their spending on DSH, and the total spending on the DSH program relative to the number of Medicaid and uninsured patients in the state in 1997. These data come in large part from a survey conducted by the Urban Institute.

Table 2 shows DSH payments by ownership and service for the DSH data we use in our analysis. Coughlin et al. show that state-owned mental health facilities represented only 2.1 percent of Medicaid patient days, but specialized state facilities received 20 percent of the DSH payments. Similarly, while private hospitals account for almost 70 percent of Medicaid patient days, they received only 37 percent of DSH payments. Through skewed allocations such as this, Coughlin et al. suggest, states were able to recapture at least 15 percent of federal DSH payments for general revenues.

\section{B. County Finances}

Data on county budgets come from the annual Survey of Government Finances and the Census of Government Finances conducted by the Bureau of the Census. We use real $(1999=100)$ per capita three-year average spending and revenue figures for 1987-1989 and 19971999. All counties are included in the survey years of 1987 and 1997 , but only $1 / 2$ to $2 / 3$ are included in (non-Census) Survey years. Not all counties report all categories of revenues or expenditures in any given year. Intergovernmental revenues are almost $\$ 400$ per capita in 1997 1999, representing more than $1 / 3$ of all county revenues. (Note that intergovernmental expenditures are much smaller, and missing for many counties.) DSH payments to hospitals (public and private) within a county are about a tenth the size of intergovernmental revenues from all sources. 
In order to examine the effect on county finances of increases in DSH payments to county hospitals, we subtract intergovernmental expenditures from intergovernmental revenues to generate net intergovernmental revenues. DSH payments to county hospitals will appear as intergovernmental revenues in the county budget, and any funds that the county hospitals return to the state will appear as intergovernmental expenditures.

\section{Infant Mortality and Low Birth Weight}

Data on infant births, birth weight, and deaths are reported at the county level in the 2003 Area Resource File compiled by the National Center for Health Workforce Analysis. We use several different measures of infant mortality. We construct 28-day and 1-year mortality in 1988-1990 and 1998-2000 from reported 3-year averages of births and deaths by race. For earlier periods we use the reported 5-year average infant mortality rate. These data are summarized in Table 1. There was a significant decline in infant mortality during this period, with 28-day mortality dropping from 5.8 per thousand in $1988-1990$ to 4.6 in $1998-2000$. We similarly construct the average incidence of low birth weight from reported 3-year averages of the number of low birth weight babies.

\section{Heart Attacks and Post-heart Attack Mortality}

Data on the incidence of heart attacks (acute myocardial infarctions, or AMIs) and postAMI mortality are constructed from the Medicare Claims data from 1989-2000, along with data through 2001 on mortality. These data include 20 percent of Medicare admissions for 1989 to 1991, and 100 percent from 1992 to 2000 . We use every fee-for-service heart attack admission to create a longitudinal cohort of 2.5 million fee-for-service enrollees age 65 or over coded with acute myocardial infarction. We assign patients to counties based on their residence (rather than where they were treated), and use linked death certificate data to see whether patients survived a 90-day or one-year window. 
From this micro-data we construct a risk-adjusted county-year level measure of post-AMI mortality by regressing 1-year and 90-day mortality on a full set of age (5-year age categories, 65-69, 70-74, etc.), race, and sex interactions, and ten co-morbidities (including cancer (metastatic and non-metastatic), diabetes, liver dysfunction, vascular disease, pulmonary disorders, dementia, and severity of heart attack). ${ }^{1}$ Thus secular changes in demographic composition, severity of AMI, and health status are controlled for. We then calculate the residual mortality for each year in our sample, 1989 to 2000 . The measures of heart attack mortality we use in the rest of our analysis thus refer to demographic and illness adjusted postAMI mortality among Medicare recipients over age 65. We use three-year averages (1989-1991 and 1998-2000) of this mortality in our analysis. In 1998-2000, 23 percent of Medicare heart attack victims died within 90 days, which represented a five-percentage-point decline from 19891991.

We construct the county-year level incidence of heart attacks similarly, adjusting for the age, sex, and race of county populations. An average of 0.78 percent of the population suffered a heart attack in 1998-2000, down from 0.81 in 1989-1991.

\section{E. Covariates}

Other county-level covariates come from the Area Resource File, including the unemployment rate, per capita income, fraction of single parent households, and population, measured as the county-level change from 1990 to 1999 . We use county population by race for 1990 and 1999 from the Bureau of the Census.

\footnotetext{
${ }^{1}$ Over this period there was a marked decline in the severity of diagnosed AMIs, with less-fatal subendocardial or non-q wave AMI rising from 25\% of all AMIs in 1989 to half in 2000 (in part because of better detection techniques). We therefore control for whether heart attacks are q wave or non-q-wave in our regression analysis.
} 
We calculate the number of beds in hospitals of different ownerships and types from the 1999 Medicare Impact files, as well as the Medicare DSH adjustment factor (which captures the fraction of poor and uninsured patients treated by each hospital) for public and private hospitals.

\section{Results}

Our empirical analysis answers three questions. First, which states were most likely to be engaging in fiscal shenanigans with DSH money through the use of inter-governmental transfers (IGT)? Second, to what extent did DSH payments in these states actually increase the resources available to county hospitals, rather than being appropriated by the state through IGTs? Third, how much did the resulting increases in DSH payments going to hospitals affect patient mortality?

\section{A. Fiscal Shenanigans and State Characteristics}

Some simple descriptive statistics suggest that states may have directed DSH payments toward government owned hospitals in order to exploit the IGT mechanism, and that the extent of this practice varied considerably across states. Figure 3 illustrates the distribution of per capita DSH payments to state hospitals, county and district hospitals, and private hospitals in the counties represented in our data. Most counties contained no state hospitals receiving DSH payments, but of the 135 that did, 32 received more than \$200 in payments to state hospitals per capita - representing more than $\$ 2$ billion in DSH payments per year. In contrast, only 7 of the 735 counties containing private hospitals that received DSH funds received more than $\$ 200$ in payments to private hospitals per capita and the vast majority received less than $\$ 25$ per capita. This skewed distribution of DSH payments to state (and to a lesser extent other public) hospitals is what would be expected if large DSH payments were being directed to public hospitals that can then divert a share of these funds back to the state. 
In addition, there was a great deal of heterogeneity across states in both the size of DSH payments and in the degree to which the payments were channeled to state and county hospitals. Figure 4 illustrates the mix of DSH payments by hospital ownership in each state. In New Hampshire less than 14 percent of DSH funds went to state hospitals while the remainder (nearly \$100 per capita) went to private hospitals. In contrast, 96 percent of DSH payments in Louisiana went to state hospitals, totaling over $\$ 150$ per capita. In many other states (including such populous states as California, Florida and Texas) a large fraction of DSH payments went to county and district hospitals. This variation is not driven solely by differences in the states' existing hospital structures: for example, only 11 percent of Louisiana's hospitals are stateowned.

Both the model and the data thus suggest that there will be variation in the degree to which different states expropriated DSH payments through IGT. In Table 3, we evaluate the plausibility of three alternative proxies that should be associated with the extent to which a state expropriated DSH funds. The first column contains results from a state-level regression in which the dependent variable is the share of state DSH contributions that were financed by local IGT (as reported in the Urban Institute survey). This measure is only available for 34 states, but if it were reported accurately this would be the most direct proxy for which states were using the IGT mechanism. The three right hand side variables in this regression were each expected to be positively related to the use if IGT because they increased the net benefits that a state could derive from the use of the IGT mechanism.

As expected, column (1) shows that states with larger populations and states with a larger share of hospital beds in county hospitals were significantly more likely to report using IGT. Consistent with the model, there was also more use of IGT in states where there was a large difference between county and private hospitals in the proportion of poor patients they served (as measured by the fraction of private hospitals serving a smaller proportion of poor patients than 
the median county hospital), although this effect was only marginally statistically significant. Similar results were found when the dependent variable was the amount of DSH going to county hospitals per Medicaid and uninsured persons in the state (column 2) or the share of DSH payments going to county hospitals as opposed to private hospitals (column 3). Thus, all three proxies for whether a state was using IGT to appropriate DSH payments have the expected positive relationship to state characteristics that should have encouraged the use of the IGT.

As another plausibility check on our three proxies, Table 4 compares the characteristics of states that report the use of inter-governmental transfers to fund DSH to those states that do not. The initial justification for these proxies was that states using IGT would have incentives to have larger DSH programs (relative to the population it was intended to serve) and to funnel funds towards county hospitals in particular. As expected, states reporting the use of IGT to fund DSH spent more than twice as much per capita on DSH, spent more than five times as much per Medicaid or uninsured patient, and spent a larger fraction of their DSH funds on county hospitals.

\section{B. DSH Payments and County Budgets}

We next estimate the effect of DSH payments on county net intergovernmental revenues, using long-differences to account for any time-invariant county characteristics. Table 5 presents estimates of equation (5). Column (1) shows that each dollar of DSH payment going to county hospitals increased net county resources by 60 cents. This estimate suggests that the average state appropriated the remaining 40 cents through IGT. Since the state share of Medicaid is at most $50 \%$, this estimate is consistent with the view that states largely recouped their original contribution to the DSH payments (i.e. largely avoided providing any net matching funds for DSH payments to county hospitals). The funds remaining with the county represent a net increase in resources available to the county, but we have no information indicating whether 
these funds were spent on hospitals themselves or other county functions. Thus, the 60 cents of effective DSH payment is an upper bound on the amount of resources that eventually went to county hospitals.

Column (2) adds DSH payments made to other hospitals located in the county, broken down by ownership of the hospital: district hospitals (semi-independent county hospitals, etc.), state hospitals, and private hospitals. The coefficient on DSH payments to county hospitals changes little from column (1). As expected, we find no significant relationship between DSH payments to state or private hospitals and net IGT: these hospitals are independent of county governments and DSH payments to them are unrelated to county budgets. The relationship between DSH payments to district hospitals and net IGT lies somewhere in the middle in terms of magnitude, reflecting the fact that some but not all district hospitals are closely affiliated with county governments and are incorporated into county budgets. Thus, these results suggest that changes in net IGT are accurately capturing the net impact of DSH payments to local government hospitals on county budgets.

The remaining columns of Table 5 estimate separate effects of DSH in states that are likely to appropriate more of the DSH payments going to county hospitals (capture=1 in equation (1)) and those that are not (capture $=0$ in equation (5)). We present results for three alternative methods of identifying states that are likely to appropriate more DSH: (1) states that reported using IGT to fund DSH, (2) states that had above average DSH per Medicaid and uninsured patient, and (3) states that had an above average share of DSH going to public hospitals. The results for these three alternative methods are qualitatively similar. In states that are likely to appropriate DSH payments, we estimate that the proportion of DSH payments to county hospitals that remain in the county is around 0.5 and is significantly below 1 , implying that these states are appropriating roughly half of DSH payments to county hospitals. In the remaining states the effect of DSH payments on net IGT are less precisely estimated, but are never 
significantly different from 1 - suggesting that these states did not appropriate DSH payments to county hospitals.

In general, our three indicators for whether a state was likely to appropriate DSH payments yield results that are consistent with expectations. Counties in states where our indicators suggest there was little opportunity to redirect DSH payments got to keep the full amount of the DSH payments they received, while counties in states where our indicators suggest greater possibilities for redirection saw their net intergovernmental revenues rise by only 50 cents for each dollar of DSH payment received. In comparing across the three indicators, identifying states based on the share of DSH going to public hospitals (the last column) appears to yield the most precise estimates. Therefore, we use these results as our preferred estimates in determining whether DSH funds were likely to affect patient outcomes.

\section{DSH Payments and Patient Mortality}

We now turn to the question of whether DSH payments had an effect on patient mortality, examining both infant mortality and post-heart attack (AMI) mortality. We begin by estimating the relationship between DSH payments and changes in mortality. After establishing these relationships, we investigate the mechanisms through which those effects might occur.

Table 6 presents estimates of regressions of the form specified in equation (6), in which the unit of observation is the county and the dependent variable is either the change in 28-day infant mortality or the change in 90-day AMI mortality for Medicare recipients between the late 1980s and the late 1990s. We report estimates from three separate specifications of the DSH variable. In columns (1) and (4) we include total DSH payments per capita made to all hospitals in the county. In the next columns, we break these into effective and ineffective DSH payments, as described earlier (with county hospital DSH payments being allocated according to the results from the last column of Table 5). The last columns break DSH payments down further in order 
to investigate whether our breakdown of county hospital DSH payments accurately identified states in which such payments had less impact on patient mortality. In particular, we break out the components of effective and ineffective DSH that are accounted for by county and district acute care hospital payments versus other hospitals.

Column (1) of Table 6 shows that for each additional \$100 per capita of DSH payments made to hospitals within a county, there was a statistically significant reduction in 28-day infant mortality of .065 percentage points, or .65 infant deaths per thousand births. Column (2) estimates that all of this effect is associated with effective DSH dollars, which are estimated to reduce infant mortality by .107 percentage points. In contrast, the estimate for ineffective DSH dollars is a third the size and statistically indistinguishable from zero. Moreover, when we further decompose DSH payments in column (3), we see that effective DSH payments to both private and county hospitals have effects on infant mortality that are similar in magnitude and individually significant, while ineffective DSH payments to both county and other types of hospitals have smaller estimated effects that are statistically insignificant. Overall, these results suggest that DSH payments for acute care hospitals that were not appropriated by the state resulted in significant improvements in infant mortality.

Similarly, column (4) shows that an additional \$100 per capita in DSH payments reduced 90-day AMI mortality by .92 percentage points, or 9.2 deaths per thousand heart attacks. Column (5) shows that effective DSH dollars were associated with a larger decline of 2.13 percentage points, while ineffective DSH dollars had virtually no effect. Column (6) again shows that effective payments to public and private hospitals had similar effects, resulting in significant improvements in AMI mortality.

How big are these reductions in mortality? A simple calculation suggests that the reductions in mortality are modest given the amount of money spent on the DSH program. The .065 percentage point reduction in infant mortality associated with each $\$ 100$ per capita increase 
in DSH spending implies that each $\$ 11$ million in DSH spending resulted in one baby saved. Similarly, the 0.92 percentage point reduction in post-AMI mortality associated with a $\$ 100$ per capita increase in DSH spending implies that $\$ 12$ million in DSH spending resulted in one life saved (a larger reduction in mortality for a smaller population of patients). Taken together, these estimates imply that one life was saved for every $\$ 6$ million dollars in DSH payments. A similar calculation based only on effective DSH payments would reduce the cost per life to about $\$ 3$ million. Of course, these crude calculations understate the total benefits resulting from DSH payments because they do not count benefits that accrue to other patient groups or from other uses to which DSH funds are diverted. Nevertheless, these estimates are in line with similar calculations done for other increases in Medicaid spending. For example, Currie and Gruber (1996) study the effects of Medicaid eligibility expansions on infant mortality, and find that while the most cost-effective targeted expansions cost almost $\$ 1$ million per infant saved, broader expansions cost more than $\$ 4$ million per infant saved. Moreover, they note that these figures are significantly less than the cost of other policies that are routinely implemented. Thus, our estimated effects are modest in terms of lives saved per dollar, but well within the range of the existing literature.

Improving access to high quality care is particularly important for poor and disadvantaged populations, given the well-documented racial disparities in health care (Smedley et al., 2003) and the fact that poor and minority populations often receive care at hospitals with below-average quality of care (Skinner et al., 2003; Weech-Maldonado et al., 2003). While we would like to examine the differential effect of DSH dollars on patients of different races, cell sizes for black infants and AMI patients are too small (and standard errors thus too big) to draw significant distinctions. For example, each $\$ 100$ per capita in effective DSH reduces black infant mortality by .19 with a standard error of .13 , and reduces white infant mortality by .07 with a standard error of .02. There are a number of reasons that one would expect DSH payments to 
have larger effects on infant mortality among blacks. First, black infants die at twice the rate of white infants and are twice as likely to be low birth weight, thus making them a population that is particularly vulnerable to changes in hospital care. In addition, black infants are more likely to be born in hospitals receiving DSH payments, since these hospitals by definition are more likely to serve poor populations. While the estimated coefficients are all consistent with a larger effect on black mortality, the standard errors are too large to reject that they are the same.

\section{Robustness}

In Tables 7 and 8 we report results from a number of alternate specifications intended to document the robustness of our estimates to reasonable changes in specification, and to investigate whether our results may be driven by spurious correlation between DSH payments and county-level trends in mortality.

Table 7 repeats our primary specification, regressing changes in infant and AMI mortality on effective and ineffective DSH (as in column 2 of Table 6), but using alternative methods of identifying states in which DSH payments to county hospitals are likely to be ineffective because of state expropriation. In columns (1) and (4) we identify states reporting a high share of nonfederal funding for DSH coming from local government IGTs as having ineffective DSH going to public hospitals (as in column (3) of Table 5). In columns (2) and (5) we identify states with high DSH per Medicaid or uninsured patient as having ineffective DSH going to public hospitals (as in column (4) of Table 5). Columns (3) and (6) reproduce the results from Table 6, using our preferred metric, which identified states based on a high share of DSH going to public hospitals (as in column (5) of Table 5). Identifying ineffective DSH using any of these alternate methods does not substantially alter the results. Thus, our results do not appear to be particularly sensitive to the metric used to identify states that appropriate DSH payments. 
A key empirical concern is that counties receiving DSH payments are likely to differ systematically from other counties (for example, having a poorer population and perhaps higher infant or AMI mortality) and that these pre-existing differences may generate different trends in mortality independent of DSH payments per se. Our finding that only effective DSH payments are related to mortality alleviates some of this concern, as it is not obvious why trends would differ only in counties receiving effective DSH. Table 8 estimates a variety of additional specifications to further allay concerns that our results are driven by such a spurious correlation between DSH payments and county-level trends in infant or AMI mortality.

The first columns of each panel of Table 8 replicate our base results from Table 6 for comparison. In the second two columns, we include a dummy variable for whether a county received any DSH payments at all in order to control for any broad differences in trends in such counties. Adding this dummy variable to the specification has no effect on our basic estimates, and the coefficient on this dummy is small and insignificant. Thus, there is a clear dose-response relationship, i.e. changes in infant and AMI mortality rates are proportional to the amount of DSH payment a county receives.

Another potential concern is that poorer hospitals with higher mortality may have experienced both larger declines over this period and higher DSH payments, without any causal connection between the two. In columns (3) and (7) we test whether this difference in the initial level of infant or AMI mortality can account for the more rapid decline in mortality associated with DSH payments. In these specification, we include mortality in the earlier period (19881990 for infant mortality, 1989-1991 for AMI mortality) on the right-hand side, and instrument for this variable (with infant mortality in 1985-1987 or AMI mortality for 1992-1994) to correct 
the estimates for measurement error. ${ }^{2}$ The coefficient on the lag is negative and significant in both cases, suggesting that there was mean reversion at the county level over this decade in both infant and post-heart attack mortality. Nevertheless, the resulting estimates of the effect of DSH payments on infant mortality are not appreciably different, with a $\$ 100$ increase in effective DSH payments resulting in a drop in infant mortality of .1 (with a robust standard error of .02). The effect of DSH payments on AMI mortality is somewhat lower after controlling for mean reversion, but still statistically significant.

Finally, we might also be concerned that we are capturing unusual trends in infant mortality because of the rapid but uneven improvements seen in the late 1980s and early 1990s with the introduction of surfactants. In column (4) we re-estimate the same specification, but substituting changes in one-year infant mortality between 1976-80 and 1988-90. Subsequent DSH dollars have no effect on mortality changes from this pre-period, with a small positive and insignificant estimated coefficient. Unfortunately, earlier data on AMI mortality is not available to do a similar robustness check.

\section{Mechanisms}

There are two fundamentally different mechanisms by which DSH funds might have reduced mortality rates among hospital patients. First, patients may have received better hospital care as the result of the additional DSH funds, either because of improved care at all hospitals or because of patients receiving their care at better hospitals (as argued in Duggan, 2000). Alternatively, the additional DSH funds may have been used for public health and outreach programs that affected hospital mortality rates through changes in patient risk factors (such as

\footnotetext{
${ }^{2}$ Unfortunately 28-day infant mortality is not available for this period in the ARF, so we use 1-year mortality. We use later AMI mortality because the first year of data we have for this variable is 1989. For this reason we are also not able to replicate column (4) for AMI mortality.
} 
prenatal care or other health behaviors) or selection in the underlying population being admitted to the hospital (as would occur if the incidence of heart attacks declined).

We take two approaches to disentangle these stories. First, we look at the incidence of the risk factors for the mortality outcomes we examine: the fraction of infants born with low birth weight (LBW) (and then mortality conditional on that fraction), and the incidence of heart attacks (and then mortality conditional on that incidence). The fraction of LBW babies should capture an important component of patient risk within hospitals. Furthermore, advancements in medical care are almost entirely manifested in reductions in mortality conditional on birth weight, not in reductions in the incidence of LBW. Reductions in the incidence of LBW can largely be attributed to improvements in maternal health and prenatal care. Similarly, the incidence of AMI within a county should capture any important selection effects that would alter the underlying health status of patients admitted with an AMI.

Columns (1) and (2) of Table 9 explore the effect of DSH payments on the change in the incidence of LBW between the late 1980s and the late 1990s. Total DSH payments in general and effective DSH spending in particular seem to have a small but significant effect on LBW. The estimate implies that a $\$ 100$ increase in effective DSH per capita is associated with a 0.26 percentage point decline in the fraction of babies born with low birth weight, relative to a base of about 7.5 percent. Thus, there is some slight evidence that effective DSH may have reduced low birth weight, presumably through improved prenatal care. Columns (3) and (4) re-estimate the effect of DSH payments on 28-day infant mortality holding the fraction LBW constant. The results are quite similar to those found in Table 6: the effect of DSH payments comes through the hospital treatment of babies even holding constant the primary risk factor. In other words, the effect of DSH payments on low birth weight is much too small to account for the relationship between DSH payments and infant mortality. Similarly, columns (7) and (8) show that there is virtually no effect of DSH payments on the incidence of heart attacks, and columns (9) and (10) 
show that holding the incidence of heart attacks constant does not change the effect of DSH payments on post-heart attack mortality.

Second, we examine longer-run mortality to see whether mortality reductions seem to come from in-hospital care or from broader factors. Most of the effect of care within the hospital should be seen in the period immediately following hospital admission, rather than months later. Columns (5) and (6) of Table 9 replicate the main specifications from Table 6 but with infant mortality between 28 days and one year as the dependent variable, while columns (11) and (12) use AMI mortality between 90 days and one year. We see no significant effects of DSH payments here - the effect of these payments on mortality seems to come through care in the hospital, not post-discharge.

Overall, these results suggest that the effect of DSH payments on infant and AMI mortality operates primarily through improved hospital care - not through prenatal care or selection (which would reduce LBW or the incidence of heart attacks and suggest little effect on mortality holding LBW or incidence constant) or through other factors that affect mortality postdischarge.

\section{CONCLUSION}

Our analysis suggests that public subsidies can be an effective mechanism for improving medical care and outcomes for the poor, but that their impact is limited by the ability of state and local government to divert the targeted funds. While funds that are diverted to other uses may result in other benefits to society (such as tax abatement or subsidies of other government programs), this dilutes the intended impact of the subsidies and thereby reduces their costeffectiveness in terms of the program's stated goals. Clearly, ongoing legislative attacks reflect the belief by many that the amount of diversion involved in the DSH program is excessive. Nevertheless, our analysis suggests that while the cup may be half empty, it is still half full. 
Despite a significant amount of diversion by the states, the Medicaid DSH program appears to have contributed to significant declines in patient mortality in many areas during the 1990s. 


\section{REFERENCES}

Centers for Medicare and Medicaid Services, Medicaid Disproportionate Share Hospital Reports, http://www.cms.gov/dsh/default.asp, accessed January 15, 2004.

Centers for Medicare and Medicaid Services, CMS Statistics, Department of Health and Human Services, 2002.

Coughlin, Teresa, and David Liska, Changing State and Federal Payment Policies for Medicaid Disproportionate Share Hospitals, Health Affairs, Volume 17, No. 3, 1998.

Coughlin, Teresa, Leighton Ku, Johnny Kim, Reforming the Medicaid Disproportionate Share Hospital Program, Health Care Financing Review, Vol. 22 No. 2, Winter 2000.

Currie, Janet, and Jonathan Gruber, Saving Babies: The Efficacy and Cost of Recent Changes in the Medicaid Eligibility of Pregnant Women, Journal of Political Economy, Vol. 104 No. 6, 1996.

Corman, Hope, Theodore Joyce, and Michael Grossman, A Cost-Effectiveness Analysis of Strategies to Reduce Infant Mortality, Medical Care, Vol. 26 No. 4, 1988.

Currie, Janet, and Jonathan Gruber, The Technology of Birth: Health Insurance, Medical Interventions, and Infant Health, NBER Working Paper 5985, 1997.

Cutler, David, Your Money or Your Life: Strong Medicine for America's Health Care System, Oxford University Press, 2004.

Cutler, David, and Ellen Meara, The Technology of Birth: Is It Worth It? Frontiers in Health Policy Research, Vol. 3, 2000.

Duggan, Mark, Hospital Ownership and Public Medical Spending, Quarterly Journal of Economics, Nov 2000.

General Accounting Office, Medicaid: States Use Illusory Approaches to Shift Program Costs to Federal Government, Letter Report, GAO/HEHS-94-133, Aug 1, 1994.

General Accounting Office, Medicaid: State Financing Schemes Again Drive Up Federal Payments, Statement of Kathryn G. Allen before the Senate Committee on Finance, GAO/T-HEHS-00-193, Sept 6, 2000.

Gruber, Jonathan, Medicaid, in Means-Tested Transfer Programs in the United States (R. Moffitt, ed.), University of Chicago Press, Chicago, 2003.

Kominski, Gerald and Stephen Long, Medicare's Disproportionate Share Adjustment and the Cost of Low-income Patients, Journal of Health Economics, Vol. 16, 1997.

$\mathrm{Ku}$, Leighton, and Teresa Coughlin, Medicaid Disproportionate Share and Other Financing Programs, Health Care Financing Review, Vol. 16 No. 3, 1995.

National Center for Health Workforce Analysis, Area Resource File, Department of Health and Human Services, 2003.

Nicholson, Sean and David Song, The Incentive Effects of the Medicare Indirect Medical Education Policy, Journal of Health Economics, Vol. 20, 2001. 
Skinner, Jonathan, Weinstein, James N., Sporer, Scott M., Wennberg, John E., Racial, Ethnic, and Geographic Disparities in Rates of Knee Arthroplasty among Medicare Patients, New England Journal of Medicine, 349(14) October 2 2003:1350-1359.

Smedley, Brian et al. (ed.), Unequal Treatment: Confronting Racial and Ethnic Disparities in Healthcare, National Academy Press, 2003.

Weech-Maldonado, R.J. , L.S. Morales , M.N. Elliot , K. Spritzer , G. Marshall and R.D. Hays, Race/Ethnicity, Language, and Patients’ Assessments of Care in Medicaid Managed Care, Health Services Research, 2003, 38(3):789-808. 


\section{FiguRE 1}

\section{State Choice of DSH and IGT}

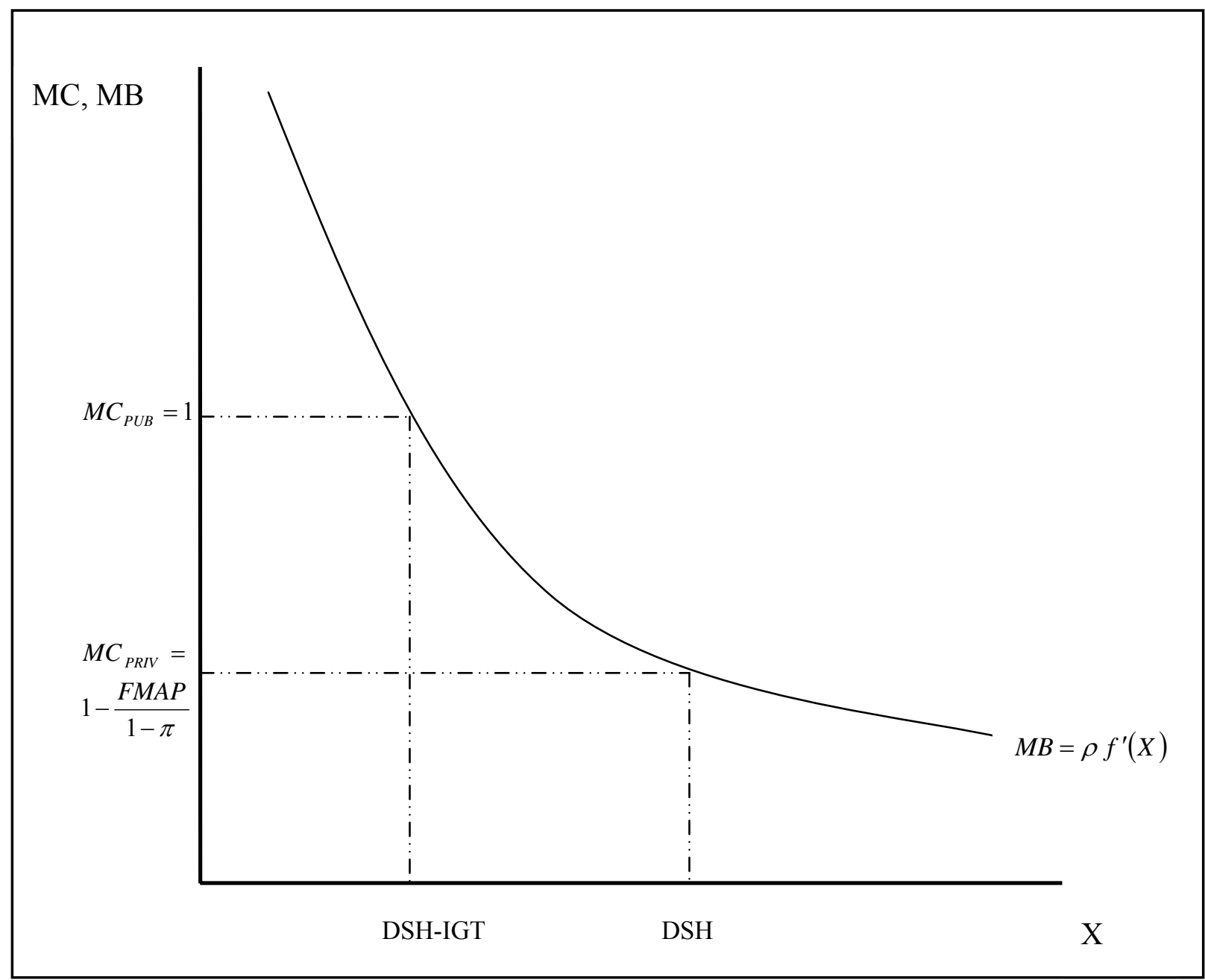




\section{FigURE 2}

\section{Effects of DSH Funds on Intergovernmental Spending}

Example: state spends $\$ 1$ million on DSH

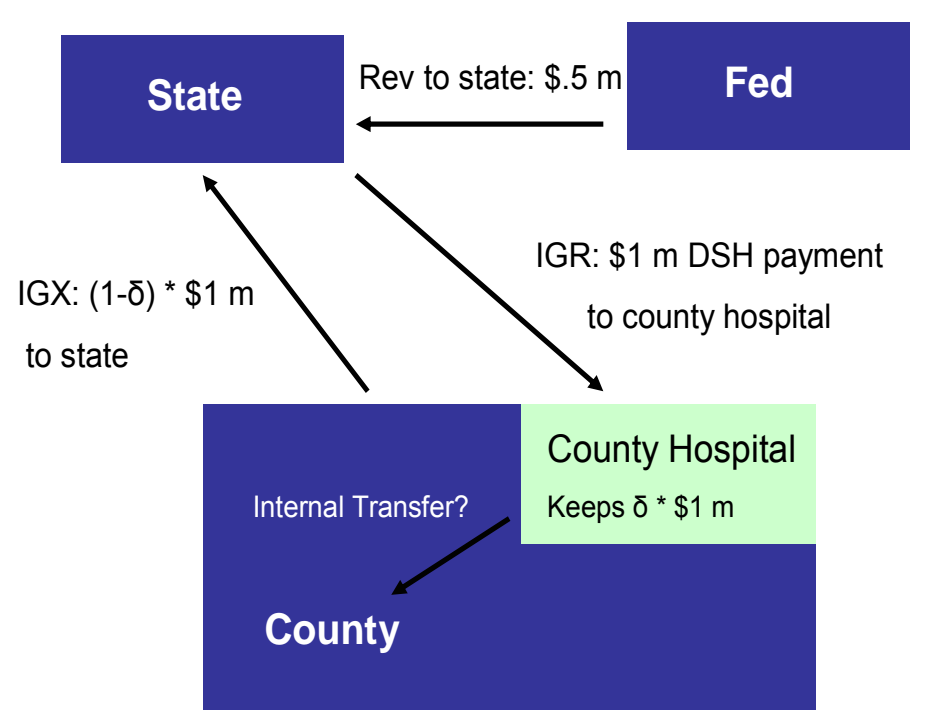




\section{Figure 3}

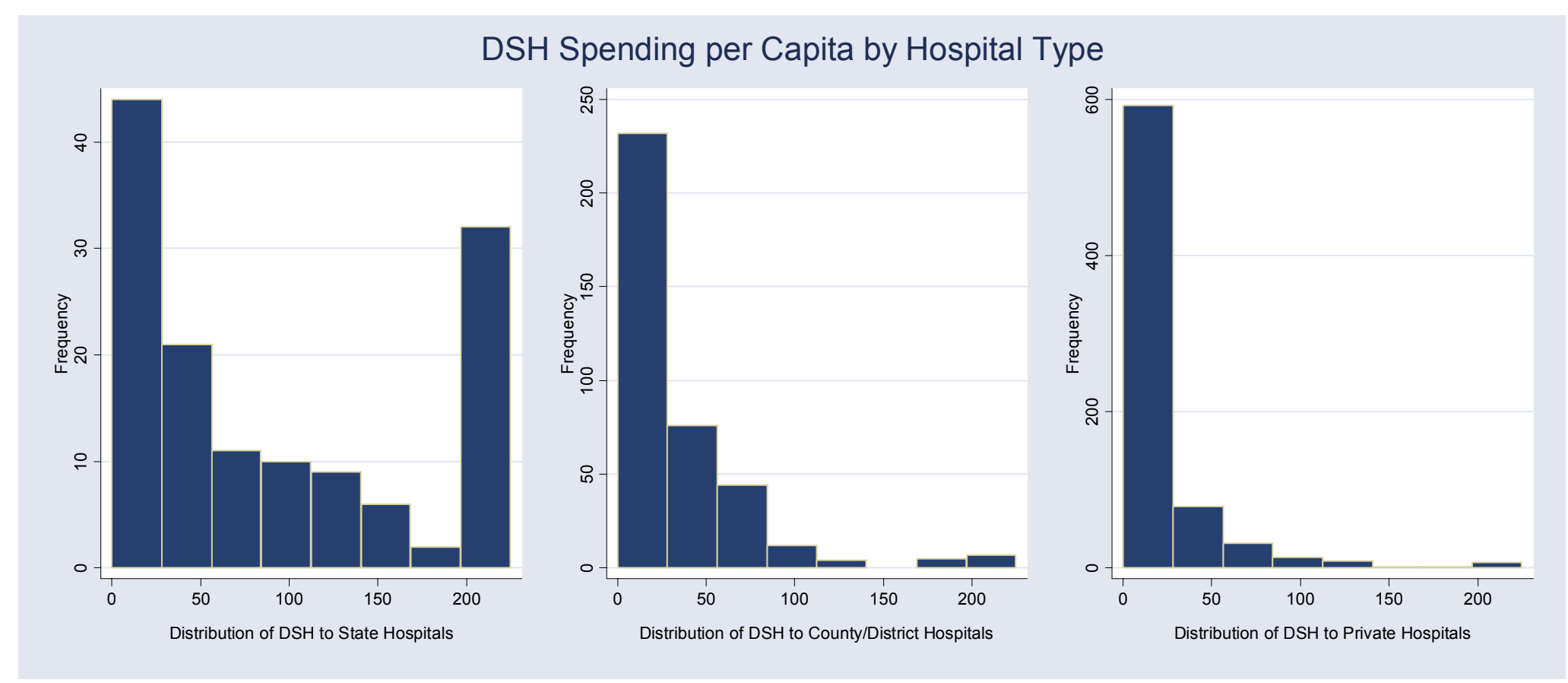




\section{Figure 4}

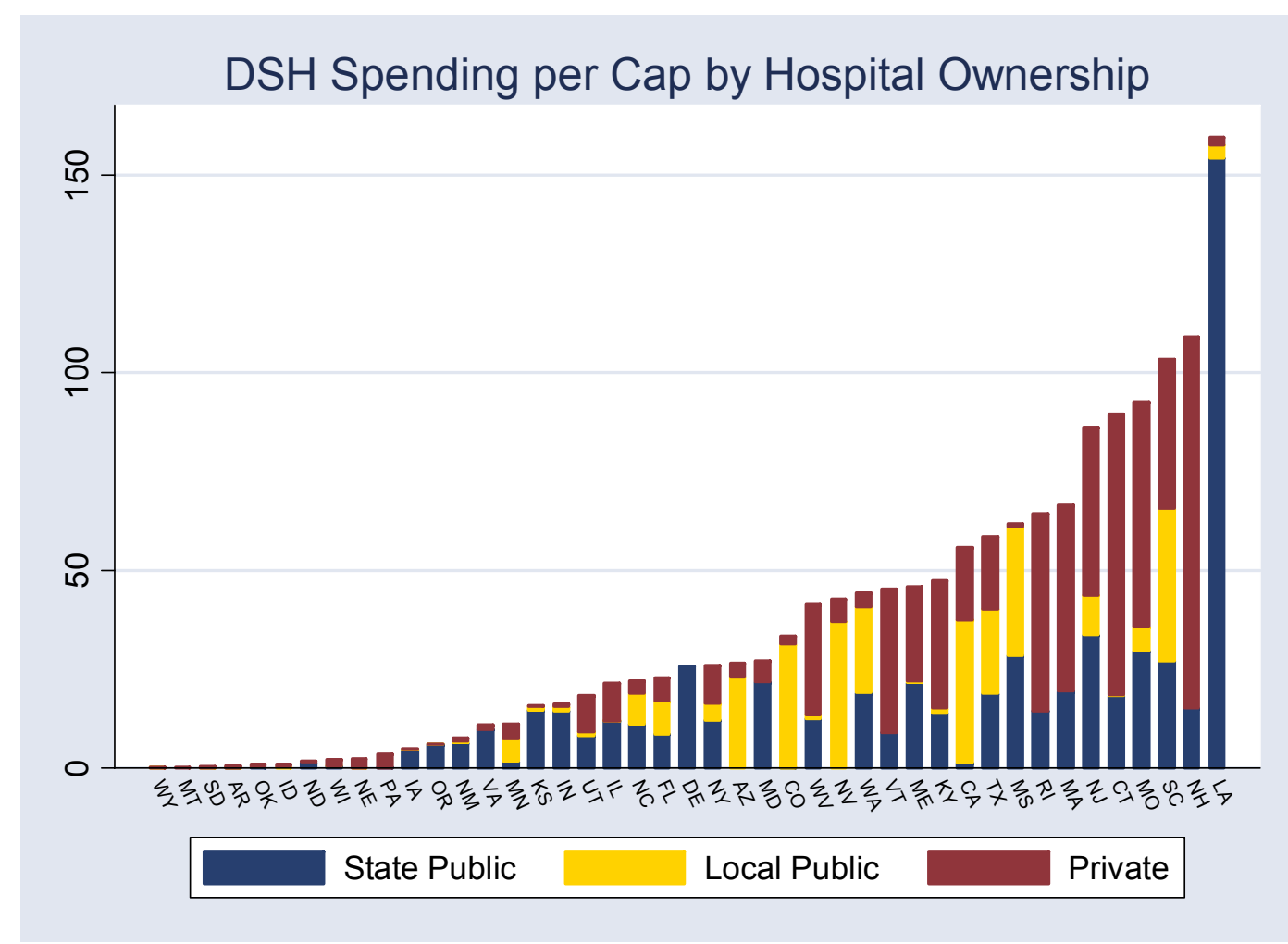




\begin{tabular}{|c|c|c|c|}
\hline & Mean & Std Dev & $\mathbf{N}$ \\
\hline \multicolumn{4}{|l|}{ County Budgets (real per capita) } \\
\hline \multicolumn{4}{|l|}{ Total Revenues } \\
\hline Annual Average, 1997/1999 & 1092 & 1198 & 2724 \\
\hline Change, $1987 / 1989$ to $1997 / 1999$ & 167 & 232 & 2716 \\
\hline \multicolumn{4}{|l|}{ Intergovernmental Revenues } \\
\hline Annual Average, 1997/1999 & 396 & 468 & 2712 \\
\hline Change, $1987 / 1989$ to $1997 / 1999$ & 66 & 99 & 2704 \\
\hline \multicolumn{4}{|l|}{ Intergovernmental Expenditures } \\
\hline Annual Average, 1997/1999 & 64 & 98 & 1778 \\
\hline Change, $1987 / 1989$ to $1997 / 1999$ & 17 & 47 & 1586 \\
\hline \multicolumn{4}{|l|}{ DSH Payments (real per capita) } \\
\hline Annual Average, 1998/2000 & 41 & 76 & 2577 \\
\hline \multicolumn{4}{|l|}{ Infant Mortality (per thousand births) } \\
\hline \multicolumn{4}{|l|}{ 28-day, All Births } \\
\hline Annual Average, 1998/2000 & 4.6 & 1.8 & 2758 \\
\hline Change, $1988 / 1990$ to $1998 / 2000$ & -1.2 & 2.0 & 2753 \\
\hline \multicolumn{4}{|l|}{ Low Birth Weight (per thousand births) } \\
\hline Annual Average, 1998/2000 & 74.4 & 15.0 & 2758 \\
\hline Change, $1988 / 1990$ to $1998 / 2000$ & 6.7 & 10.1 & 2753 \\
\hline \multicolumn{4}{|l|}{ AMI Mortality (90-days, risk adjusted) } \\
\hline Annual Average, 1998/2000 & 0.23 & 0.03 & 2520 \\
\hline Change, $1989 / 1991$ to $1998 / 2000$ & -0.05 & 0.07 & 2478 \\
\hline \multicolumn{4}{|c|}{ Incidence of AMI (per thousand, age-sex-race adjusted) } \\
\hline Annual Average, 2000 & 7.8 & 2.7 & 2524 \\
\hline Change, $1989 / 1991$ to $1998 / 2000$ & -0.3 & 2.4 & 2522 \\
\hline
\end{tabular}

Notes: Budget data are measured in real $(1999=100)$ per capita dollars and come from the Survey of Government Finances.

DSH based on CMS hospital-level DSH data merged with AHA identifiers and aggregated to county level.

Infant mortality and LBW data are from the Area Resource File.

AMI mortality from Medicare Claims data, age, sex, race, illness adjusted.

All means are weighted by 1998 population, except mortality (weighted by incidence). 
Table 2: DSH Payments by Type of Hospital

\begin{tabular}{|c|c|c|c|c|}
\hline \multicolumn{5}{|c|}{$\begin{array}{l}\text { Millions of Dollars } \\
\text { (share of total) }\end{array}$} \\
\hline & State & $\begin{array}{c}\text { County \& } \\
\text { Local Public }\end{array}$ & NFP & FP \\
\hline $\begin{array}{l}\text { General/ } \\
\text { Children's }\end{array}$ & $\begin{array}{r}1,324 \\
(.14)\end{array}$ & $\begin{array}{r}2,708 \\
(.29)\end{array}$ & $\begin{array}{r}2,862 \\
(.30)\end{array}$ & $\begin{array}{l}354 \\
(.04)\end{array}$ \\
\hline Other & $\begin{array}{r}1,809 \\
(.19)\end{array}$ & $\begin{array}{c}57 \\
(.01)\end{array}$ & $\begin{array}{c}31 \\
(.00)\end{array}$ & $\begin{array}{r}89 \\
(.01)\end{array}$ \\
\hline
\end{tabular}

Total for our sample (matched to AHA IDs):

$\$ 9.5$ billion

Notes: $\quad$ DSH data posted by CMS, matched to AHA hospital ID to obtain county, type, and service of hospital, then aggregated to county level. 
Table 3: Predictors of Financial "Shenanigans"

\begin{tabular}{lccc}
\hline & $\begin{array}{c}\text { Share of State Funds from } \\
\text { Local Intergovernmental } \\
\text { Transfers }\end{array}$ & $\begin{array}{c}\text { County DSH per } \\
\text { Medicaid/Uninsured } \\
\text { Person }\end{array}$ & $\begin{array}{c}\text { Share of County and } \\
\text { Private Hospital DSH } \\
\text { Going to Counties }\end{array}$ \\
\cline { 2 - 4 } $\begin{array}{l}\text { Difference in Fraction of Poor } \\
\text { Patients Served by County } \\
\text { and Private Hospitals }\end{array}$ & 0.44 & 50.7 & 0.24 \\
Public Share of Hospital & $(.24)$ & $(24.4)$ & $(.16)$ \\
Beds & 1.11 & 94.7 & $(.31)$ \\
Log of Population & $(.44)$ & 10.9 & 0.92 \\
& 0.15 & $(4.8)$ & $(.04)$ \\
Mean of Dependent Variable & $(.04)$ & 21.0 & 0.20 \\
N & 0.18 & 43 & 42 \\
\hline
\end{tabular}

Notes: State-level analysis.

DSH spending data aggregated to county-level, based on CMS hospital-level DSH data merged with AHA

identifiers, measured in real per capita dollars (1998-2000).

DSH/Medicaid and reported use of IGTs for 1997 from Coughlin, Ku, and Kim (2000)

Data on overlap of poverty distribution (based on Medicare DSH adjustment factor) and on hospital beds from Medicare Impact Reports. 
Table 4: Characteristics of States that Use Intergovernmental Transfers to Fund DSH

\begin{tabular}{|c|c|c|c|c|}
\hline \multirow[b]{3}{*}{ DSH (\$ Per Capita) } & \multicolumn{2}{|c|}{ States Not Using IGT } & \multicolumn{2}{|c|}{ States Using IGT } \\
\hline & Mean & Std Dev & Mean & Std Dev \\
\hline & 22.9 & 34.7 & 57.1 & 30.4 \\
\hline To State Hospitals & 13.4 & 31.7 & 18.6 & 10.2 \\
\hline Share of Total & 0.59 & & 0.33 & \\
\hline $\begin{array}{l}\text { To County Hospitals } \\
\text { Share of Total }\end{array}$ & $\begin{array}{r}2.0 \\
0.09\end{array}$ & 5.5 & $\begin{array}{l}11.5 \\
0.20\end{array}$ & 13.6 \\
\hline $\begin{array}{l}\text { DSH to County Hospitals Per } \\
\text { Medicaid/Uninsured Patient }\end{array}$ & 8.3 & 22.2 & 50.4 & 46.2 \\
\hline $\begin{array}{l}\text { County Share of DSH to County and } \\
\text { Private Hospitals }\end{array}$ & 0.17 & 0.27 & 0.34 & 0.32 \\
\hline $\mathrm{N}$ & 23 & & 11 & \\
\hline
\end{tabular}

Notes: State-level analysis.

DSH expenditures are measured in real per capita dollars.

DSH spending data aggregated to county-level, based on CMS hospital-level

DSH data merged with AHA identifiers 1998-2000).

DSH/Medicaid and reported use of IGTs for 1997 from Coughlin, Ku, and 


\begin{tabular}{|c|c|c|c|c|c|}
\hline & \multicolumn{5}{|c|}{ Change in Net Intergovernmental Revenues } \\
\hline & $(1)$ & $(2)$ & (3) & (4) & $(5)$ \\
\hline Change in DSH to County Hospitals & $\begin{array}{r}0.60 \\
(.13)\end{array}$ & $\begin{array}{l}0.63 \\
(.13)\end{array}$ & & & \\
\hline Change in DSH to District Hospitals & & $\begin{array}{l}0.42 \\
(.17)\end{array}$ & & & \\
\hline Change in DSH to State Hospitals & & $\begin{array}{l}0.08 \\
(.11)\end{array}$ & & & \\
\hline Change in DSH to Private Hospitals & & $\begin{array}{l}0.11 \\
(.16)\end{array}$ & & & \\
\hline $\begin{array}{l}\text { Change in DSH to County * Dummy for States with High Local } \\
\text { Intergovernmental Transfer Share }\end{array}$ & & & $\begin{array}{l}0.51 \\
(.09)\end{array}$ & & \\
\hline $\begin{array}{l}\text { Change in DSH to County * Dummy for States with Low Local } \\
\text { Intergovernmental Transfer Share }\end{array}$ & & & $\begin{array}{l}2.23 \\
(.71)\end{array}$ & & \\
\hline $\begin{array}{l}\text { Change in DSH to County * Dummy for States with High } \\
\text { County DSH per Medicaid/Uninsured Patient }\end{array}$ & & & & $\begin{array}{l}0.55 \\
(.12)\end{array}$ & \\
\hline $\begin{array}{l}\text { Change in DSH to County * Dummy for States with Low } \\
\text { County DSH per Medicaid/Uninsured Patient }\end{array}$ & & & & $\begin{array}{r}1.77 \\
(1.03)\end{array}$ & \\
\hline $\begin{array}{l}\text { Change in DSH to County * Dummy for States with High } \\
\text { Share of County and Private Hospital Spending to Counties }\end{array}$ & & & & & $\begin{array}{l}0.55 \\
(.12)\end{array}$ \\
\hline $\begin{array}{l}\text { Change in DSH to County * Dummy for States with Low Share } \\
\text { of County and Private Hospital Spending to Counties }\end{array}$ & & & & & $\begin{array}{l}1.95 \\
(.54)\end{array}$ \\
\hline Probability Coefficients Equal & & & 0.014 & 0.242 & 0.010 \\
\hline Observations & 1420 & 1420 & 1261 & 1420 & 1420 \\
\hline
\end{tabular}

Notes: County-level analysis. Change is from late 80s to late 90s, measured as 3-year averages. County budget data from annual Survey of Government Finances.

DSH/Medicaid and reported IGT use from Coughlin, Ku, and Kim (2000)

DSH data aggregated to county-level, based on CMS hospital-level DSH data merged with AHA identifiers. All expenditures are measured in real per capita dollars.

Covariates include fraction black, unemployment rate, per capita income, and state fixed effects.

Standard errors in parentheses, clustered at state level. Regressions weighted by population. 
Table 6: The Effect of Change in Per Capita DSH Spending on Mortality

\begin{tabular}{|c|c|c|c|c|c|c|}
\hline & \multicolumn{3}{|c|}{$\begin{array}{l}\text { Change in 28-day Infant Mortality } \\
\text { (Effect of \$100 Change) }\end{array}$} & \multicolumn{3}{|c|}{$\begin{array}{l}\text { Change in 90-day AMI Mortality } \\
\text { (Effect of \$100 Change) }\end{array}$} \\
\hline & \multicolumn{3}{|c|}{ All Births } & \multicolumn{3}{|c|}{ All AMIs } \\
\hline & $(1)$ & $(2)$ & (3) & (4) & (5) & (6) \\
\hline Change in DSH to All Hospitals & $\begin{array}{r}-0.065 \\
(.021)\end{array}$ & & & $\begin{array}{r}-0.92 \\
(.64)\end{array}$ & & \\
\hline $\begin{array}{l}\text { Change in "Effective" DSH } \\
\text { (Using low share to public hospitals) }\end{array}$ & & $\begin{array}{r}-0.106 \\
(.028)\end{array}$ & & & $\begin{array}{r}-2.13 \\
(.58)\end{array}$ & \\
\hline $\begin{array}{l}\text { Change in DSH to Private General/ } \\
\text { Children's Hospitals }\end{array}$ & & & $\begin{array}{r}-0.109 \\
(.037)\end{array}$ & & & $\begin{array}{r}-1.39 \\
(.78)\end{array}$ \\
\hline $\begin{array}{l}\text { Change in Effective DSH to County/ District } \\
\text { General/ Children's Hospitals }\end{array}$ & & & $\begin{array}{r}-0.106 \\
(.025)\end{array}$ & & & $\begin{array}{r}-3.94 \\
(1.64)\end{array}$ \\
\hline $\begin{array}{l}\text { Change in "Ineffective" DSH } \\
\text { (Using high share to public hospitals) }\end{array}$ & & $\begin{array}{r}-0.033 \\
(.022)\end{array}$ & & & $\begin{array}{r}-0.09 \\
(.83)\end{array}$ & \\
\hline $\begin{array}{l}\text { Change in Ineffective DSH to County/ } \\
\text { District General/ Children's Hospitals }\end{array}$ & & & $\begin{array}{r}-0.021 \\
(.080)\end{array}$ & & & $\begin{array}{r}0.78 \\
(3.11)\end{array}$ \\
\hline Change in Other Ineffective DSH & & & $\begin{array}{r}-0.034 \\
(.022)\end{array}$ & & & $\begin{array}{r}-0.08 \\
(.83)\end{array}$ \\
\hline Probability Effective DSH = Ineffective DSH & & 0.009 & & & 0.037 & \\
\hline Observations & 2520 & 2517 & 2517 & 2477 & 2474 & 2474 \\
\hline
\end{tabular}

Notes:

County-level analysis. Change is from late 80s to late 90s, measured as 3-year averages.

Data from ARF (infant mortality and covariates), Medicare Claims (AMI), CMS (DSH).

Mortality measured in percentage points. AMI mortality adjusted for age, sex, race, and illness.

Covariates include fraction black, unemployment rate, per capita income, and state fixed effects.

Standard errors in parentheses, clustered at state level. Regressions weighted based on births or AMI in each period.

"Effective" DSH defined following column (5) of Table 5. 
Table 7: Impact of Different Measures of Effective DSH

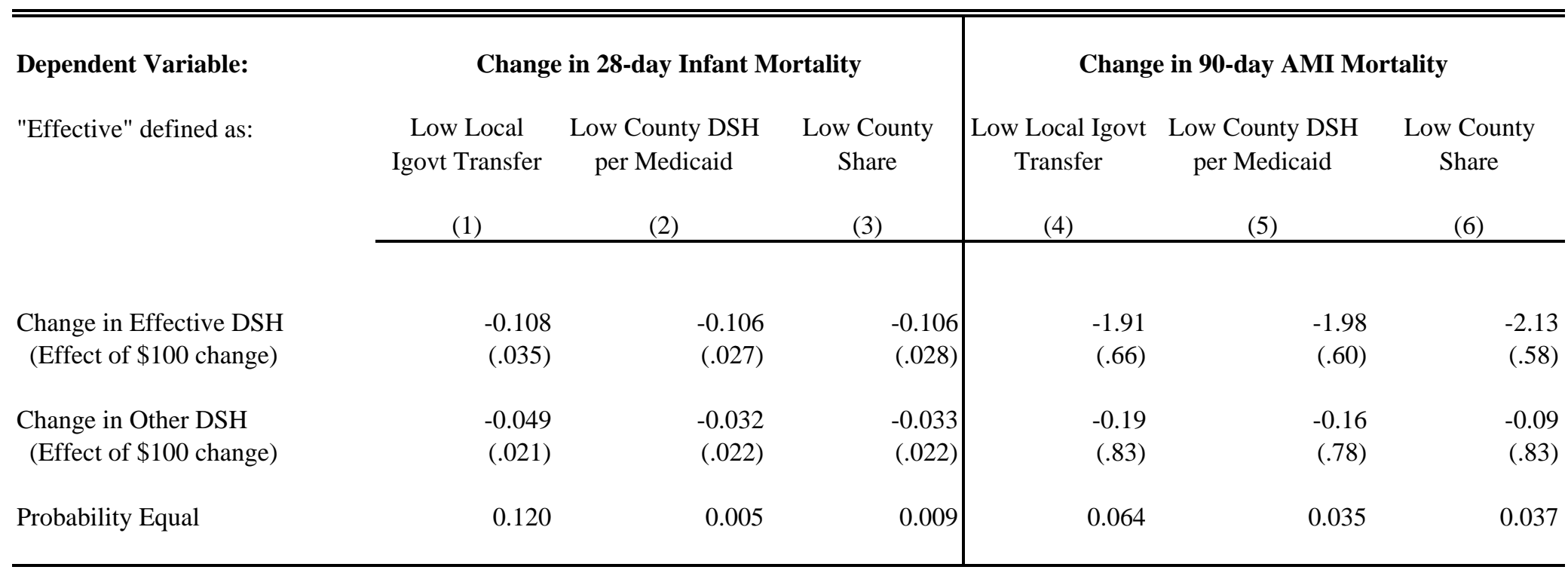

\section{Notes:}

County-level analysis. Change is from late 80 s to late 90s, measured as 3-year averages.

Data from ARF (infant mortality and covariates), Medicare Claims (AMI), CMS (DSH).

Mortality measured in percentage points. AMI mortality adjusted for age, sex, race, and illness.

Covariates include fraction black, unemployment rate, per capita income, and state fixed effects.

Standard errors in parentheses, clustered at state level. Regressions weighted based on births or AMI in each period.

"Effective DSH" measures correspond to Table 3. 
Table 8: Robustness Checks

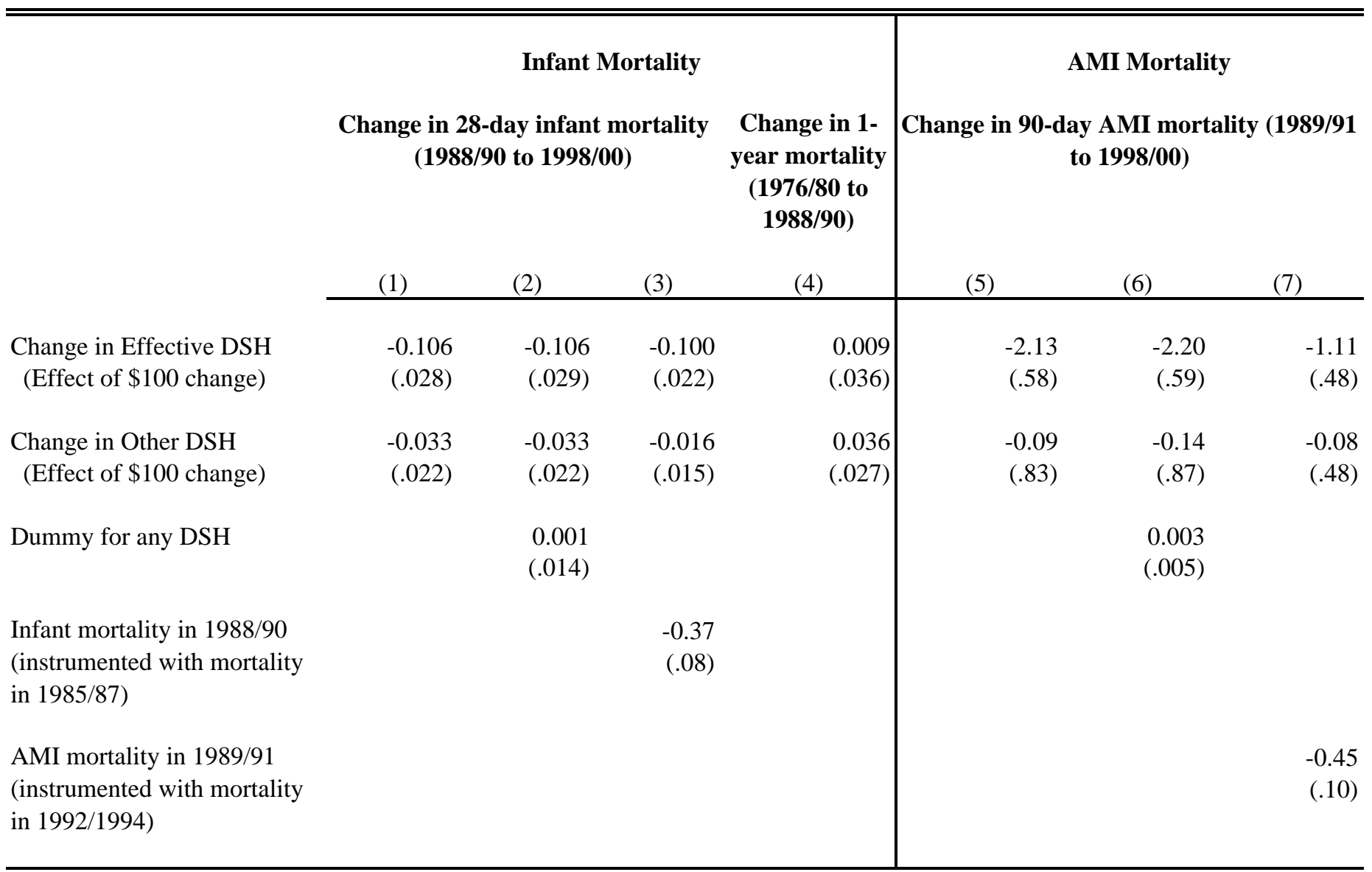

Notes:

County-level analysis. Change is from late 80s to late 90s, measured as 3-year averages.

Data from ARF (infant mortality and covariates), Medicare Claims (AMI), CMS (DSH).

Mortality measured in percentage points. AMI mortality adjusted for age, sex, race, and illness.

Covariates include fraction black, unemployment rate, per capita income, and state fixed effects.

Standard errors in parentheses, clustered at state level. Regressions weighted based on births or AMI in each period.

"Effective" DSH defined following column (5) of Table 5. 
Table 9: How DSH Spending Affects Mortality

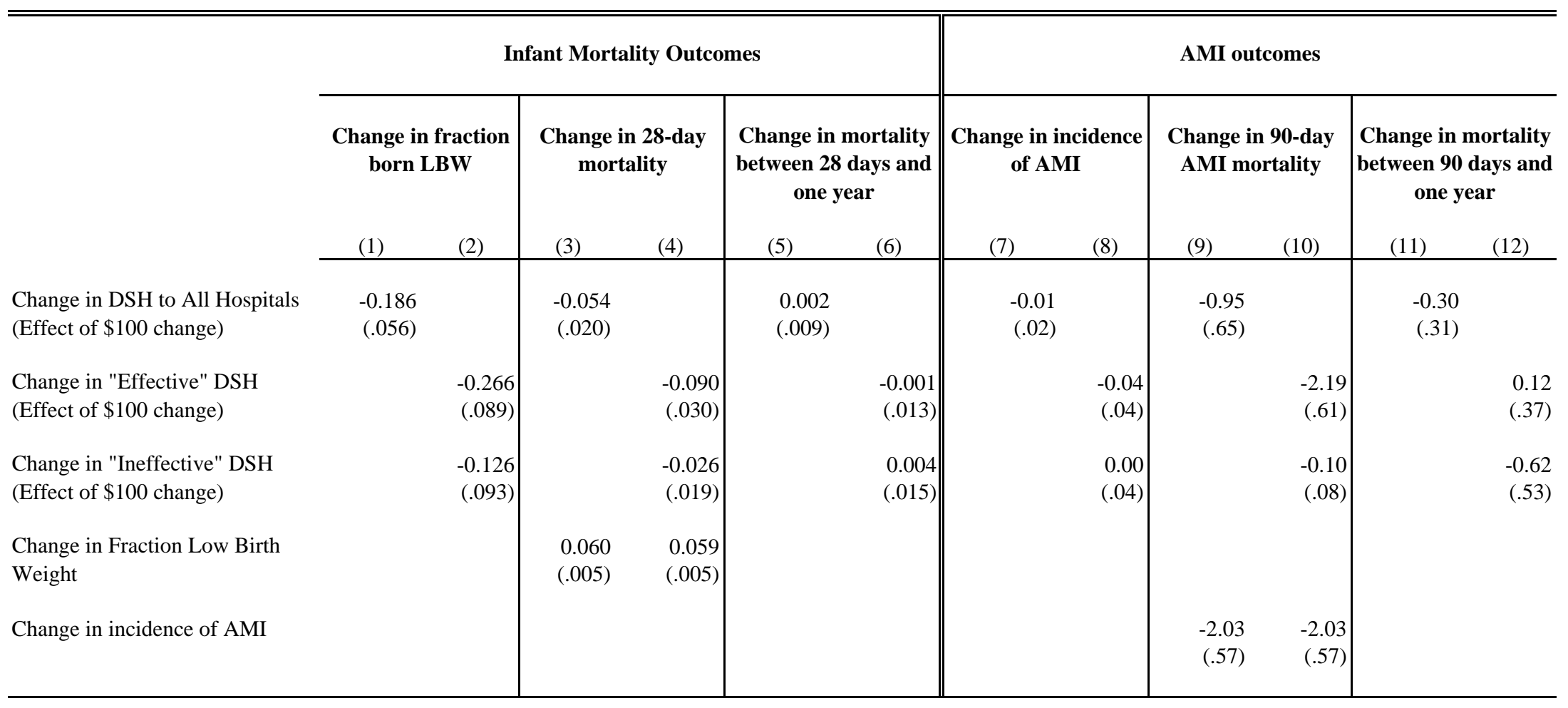

Notes:

County-level analysis. Change is from late 80s to late 90s, measured as 3-year averages.

Data from ARF (infant mortality and covariates), Medicare Claims (AMI), CMS (DSH).

Mortality measured in percentage points. AMI mortality adjusted for age, sex, race, and illness.

Covariates include fraction black, unemployment rate, per capita income, and state fixed effects.

Standard errors in parentheses, clustered at state level. Regressions weighted based on births or AMI in each period.

"Effective" DSH defined following column (5) of Table 5. 